\title{
ЭКОЛОГО-ЭТНИЧЕСКИЕ ОСОБЕННОСТИ МИКРОЭЛЕМЕНТНОГО СТАТУСА КРОВИ У БЕРЕМЕННЫХ ЖЕНЩИН ПРИАМУРЬЯ
}

\author{
С.В. Супрун, Г.П. Евсеева*, О.С. Кудряшова, Н.И. Кудерова, О.А. Лебедько \\ Хабаровский филиал Федерального государственного бюджетного научного учреждения \\ «Дальневосточный научный центр физиологии и патологии дыхания» - \\ Научно-исследовательский институт охраны материнства и детства \\ *e-mail: evceewa@yandex.ru
}

РЕЗЮМЕ. С целью оценки микроэлементного статуса проведено обследование крови методом плазменной спектрометрии у 204 беременных женщин коренного и пришлого населения Приамурья. Выявлено, что у пришлых сельских беременных в сравнении с городскими женщинами достоверно повышены уровни $\mathrm{Cu}, \mathrm{Zn}, \mathrm{Se}$ и $\mathrm{Cd}, \mathrm{Pb}$ в сыворотке, сопровождающиеся снижением концентрации $\mathrm{Zn}, \mathrm{Se}$ и увеличением $\mathrm{Cd}, \mathrm{Pb}$ в клетках крови. Для коренных беременных женщин характерна тенденция к снижению $\mathrm{Cu}, \mathrm{Zn}, \mathrm{Se}, \mathrm{Pb}$ и накоплению Cd в сыворотке, к снижению $\mathrm{Cu}, \mathrm{Pb}$ и повышению $\mathrm{Zn}, \mathrm{Se}, \mathrm{Cd}$ в клетках крови в сравнении с пришлыми, проживающими в одной сельской местности. Выявленный дисбаланс связан с использованием разных источников воды, продуктов питанияи требует проведения дополнительной коррекции витаминно-минеральными комплексами.

КЛЮЧЕВЫЕ СЛОВА: беременные женщины, микроэлементы, коренное и пришлое население.

\section{ECOLOGICAL AND ETHNIC FEATURES OF THE MICROELEMENT STATUS OF BLOOD IN PREGNANT WOMEN OF PRIAMURIE}

\author{
S.V. Suprun, G.P. Evseeva*, O.S. Kudryashova, N.I. Kuderova, O.A. Lebed'ko \\ Khabarovsk Branch of Far Eastern Scientific Center of Physiology and Pathology \\ of Respiration Research Institute of Maternity and Childhood Protection, Khabarovsk, Russia \\ *e-mail: evceewa@yandex.ru
}

ABSTRACT. In order to assess the microelement status, a blood examination of 209 pregnant women of the indigenous and newcomer population of Priamuriewas carried out by plasma spectrometry. It was revealed that in comparison to newcomer urban women, newcomer pregnant women from rural areas had significantly increased levels of $\mathrm{Cu}, \mathrm{Zn}, \mathrm{Se}$ and $\mathrm{Cd}, \mathrm{Pb}$ in the serum, accompanied by a decrease in the concentration of $\mathrm{Zn}, \mathrm{Se}$ and an increase in $\mathrm{Cd}$, $\mathrm{Pb}$ in blood cells. Indigenous pregnant women are characterized by a tendency towards a decrease in $\mathrm{Cu}, \mathrm{Zn}, \mathrm{Se}, \mathrm{Pb}$ and accumulation of $\mathrm{Cd}$ in the serum; a decrease in $\mathrm{Cu}, \mathrm{Pb}$ and an increase in $\mathrm{Zn}, \mathrm{Se}, \mathrm{Cd}$ in blood cells in comparison to newcomers living in the same rural area. The revealed imbalance happens because of different sources of water, food, and requires additional correction of vitamin and mineral complexes.

KEYWORDS: pregnant women, trace elements, indigenous and newcomer population.

\section{ВВЕДЕНИЕ}

В современных экологических условиях изменения окружающей среды человека вызваны сложным переплетением технико-экономических и социальных факторов, воздействие которых в итоге приводит к нарушению экосистем. Формирование патологии происходит в наиболее слабом структурно-функциональном звене человеческой популяции: у восприимчивых контингентов, в первую очередь беременных женщин и детей. Это определяет актуальность изучения региональных особенностей механизмов формирования системы «мать-плод», ее влияния на развитие органов и систем, возникновение акклиматизационного дисбаланса и субкомпенсированной модификации основных фундаментальных биологических процессов (пролиферации, дифференцировки, апоптоза, клеточной сигнальной регуляции и др.), жизнеспособность новорожденного и ребенка. Особенности обмена веществ в отдельных регионах, обусловленные ландшафтно-биогеохимическим своеобразием, дополняются влиянием климата, свойственного данному району. В экстремальных условиях воздействия, которые характерны и для Приамурья, физиологические механизмы адаптивной перестройки организма приводят к изменениям микроэлементного гомеостаза. В связи с представленными данными важной с становится проблема антагонизма как токсических, так и эссенциальных микроэлементов, нарушение металлолигандных взаимоотношений у беременной и плода. Прогноз таких последствий и их предупреждение особенно важны в акушерстве и педиатрии (Сокур, Дубровина, 2015; Geraghty et al., 2015; Lewicka et al., 2017). 
Цель работы - выявить и оценить особенности микроэлементного статуса крови у беременных женщин Приамурья с учетом экологических и этнических аспектов для обоснования индивидуальной коррекции витаминно-минеральными комплексами.

\section{МАТЕРИАЛЫ И МЕТОДЫ}

Обследовано 212 беременных женщин пришлого (европеоиды) и коренного (нанайки) населения, проживающих в городской и сельской местности Приамурья, при первичном обращении и наличии информированного согласия на проведение исследований. Критериями формирования групп служили экологическая (проживание в условиях города и села) и этническая (пришлые европеоиды и коренные нанайки) составляющие. Были сформированы три группы беременных: 1-я группа - пришлые городские $(n=72)$, 2-я группа - пришлые сельские $(n=72)$, 3-я группа - коренные сельские $(n=68)$. Микроэлементный состав (эссенциальные: $\mathrm{Cu}, \mathrm{Zn}, \mathrm{Se}$; токсические: $\mathrm{Cd}, \mathrm{Pb}$ ) определяли с соблюдением пробоподготовки универсальным методом плазменной спектрометрии на приборе масс-спектрометре ICP-MS Elan 9000 (Канада) в сыворотке и форменных элементах крови, представляющих тканевой уровень, что является диагностически более значимыми и нформативным.

Статистическую обработку и оценку полученных данных проводили с использованием программных средств пакета «Statistica» (версия 10), вычислением основных описательных характеристик, достоверности различий в группах с точностью $p<0,05$.

\section{РЕЗУЛЬТАТЫ И ОБСУЖДЕНИЕ}

При сравнении данных крови 1-й и 2-й групп беременных изучались экологические особенности микроэлементного статуса. В сыворотке определено следующее достоверное содержание эссенциальных элементов: у пришлых городских беременных $\mathrm{Cu}=1804,0 \pm 115,5$ мкг/л, $\mathrm{Zn}=2610,6 \pm 354,9$ мкг/л, $\mathrm{Se}=64,1 \pm 6,3$ мкг/л; у пришлых сельских женщин более высокие показатели $\mathrm{Cu}=3429,1 \pm 358,1$ мкг/л $(p=0,0001), \mathrm{Zn}=4114,5 \pm 548,2$ мкг/л $(p=0,028)$ и $\mathrm{Se}=77,1 \pm 7,9$ мкг/л. В форменных элементах крови городских жительниц выявлено: $\mathrm{Cu}=2,46 \pm 0,29$ мкг $/ г, \mathrm{Zn}=27,68 \pm 1,04$ мкг/г, $\mathrm{Se}=0,422 \pm 0,0139$ мкг/г; пришлых села: $\mathrm{Cu}=2,65 \pm 0,38$ мкг/г $(p>0,05), \mathrm{Zn}=23,08 \pm 1,17$ мкг/г $(p=0,006), \mathrm{Se}=0,314 \pm 0,018$ мкг/г $(p=0,00002)$. Кроме эссенциальных микроэлементов, определяли наиболее частые токсиканты $\mathrm{Cd}$ и $\mathrm{Pb}$, которые у пришлых сельских беременных выявлены в достоверно большем содержании: $\mathrm{Cd}=$ $=1,101 \pm 0,461$ мкг/л и $\mathrm{Pb}=44,82 \pm 12,4$ мкг/л, чем у жительниц города: $\mathrm{Cd}=0,086 \pm 0,068$ мкг/л $(p=0,036)$ и $\mathrm{Pb}=13,03 \pm 6,56$ мкг/л $(p=0,030)$. В форменных элементах крови сохранялась такая же направленность: в группе сельских пришлых беременных $\mathrm{Cd}=0,004 \pm 0,001$ мкг $/ \Gamma$ и $\mathrm{Pb}=0,129 \pm 0,0312$ мкг/г - больше, чем у городских женщин, у которых $\mathrm{Cd}=0,001 \pm 0,0003$ мкг/г $(p=0,0044)$ и $\mathrm{Pb}=0,061 \pm 0,008$ мкг/Г $(p=0,0436)$. Этническая особенность микроэлементного статуса беременных женщин коренного населения (нанаек) выявлена при сравнении показателей крови с группой сельских пришлых жительниц, проживающих практически в одинаковых климатогеографических условиях, и заключалась в тенденции к снижению в сыворотке $\mathrm{Cu}=3248,2 \pm 346,8$ мкг/л, $\mathrm{Zn}=3812,3 \pm 533,3$ мкг/л, $\mathrm{Se}=74,3 \pm 7,3$ мкг/л, $\mathrm{Pb}=23,81 \pm 6,12$ мкг/л при достоверном повышении $\mathrm{Cd}=3,74 \pm 1,37$ мкг/л $(p=0,05)$. При сравнительном анализе данных в форменных элементах крови определена тенденция к снижению $\mathrm{Cu}=1,945 \pm 0,0003$ мкг $/ \Gamma$ и $\mathrm{Pb}=$ $0,110 \pm 0,026$ мкг/г, к повышению $\mathrm{Zn}=23,94 \pm 1,51$ мкг/г, $\mathrm{Se}=0,325 \pm 0,021$ мкг/г и $\mathrm{Cd}=0,005 \pm 0,001$ мкг/г. Полученные данные косвенно показывают и объясняют причинно-следственные связи между элементным составом крови и использованием различных источников воды, продуктов питания в условиях города и села,

\section{ВЫВОДЫ}

Изученные некоторые особенности микроэлементного статуса крови у беременных пришлого и коренного населения Приамурья носят эколого-этнический характер и проявляются достоверным повышением уровней $\mathrm{Cu}, \mathrm{Zn}, \mathrm{Se}$ и $\mathrm{Cd}, \mathrm{Pb}$ в сыворотке, сопровождающиеся снижением концентрации $\mathrm{Zn}$, $\mathrm{Se}$ и увеличением $\mathrm{Cd}, \mathrm{Pb}$ в клетках крови у пришлых сельских беременных в сравнении с городскими 
женщинами. У коренных беременных женщин (нанаек) определена тенденция к снижению $\mathrm{Cu}, \mathrm{Zn}, \mathrm{Se}$, $\mathrm{Pb}$, накоплению $\mathrm{Cd}$ в сыворотке, а также снижению $\mathrm{Cu}, \mathrm{Pb}$, повышению $\mathrm{Zn}, \mathrm{Se}, \mathrm{Cd}$ в клетках крови в сравнении с пришлыми женщинами, проживающими в одной сельской местности. Выявленный дисбаланс эссенциальных и токсических микроэлементов является обоснованием дополнительной индивидуальной коррекции установленных изменений и требует проведения дальнейших исследований по контролю и оценке эффективности профилактических мероприятий в период гестации и на этапе прегравидарной подготовки.

\section{Список литературы / References}

1. Сокур Т.Н., Дубровина Н.В. Витамины и минералы: значимость приема во время беременности. Гинекология. 2015; 17(6): 27-31. [Sokur T.N., Dubrovina N.V. Vitamins and minerals: importance of use during pregnancy. Gynecology. 2015; 17(6): 27-31. (in Russian.)].

2. Geraghty A.A., Lindsay K.L., Alberdi G., et al. Nutrition During Pregnancy Impacts Offspring's Epigenetic Status-Evidence from Human and Animal Studies. Metab Insights.2015, 8(Suppl1): 41-47.

3. Lewicka I., Kocyłowski R., Grzesiak M., et al. Selected trace elements concentrations in pregnancy and their possible role - literature review. Ginekologia Polska. 2017; 88(9): 509-514. 